\title{
Marginal Adaptation of Metal Ceramic Crowns Cast from Four Different Base Metal Alloys before and after Porcelain Application
}

Ali Hafezeqoran ${ }^{1}$, Roodabeh Koodaryan $^{1^{*}}$, Ali Esmaili $^{2}$, Heydar Noori $^{3}$, Alireza Shahbaz $^{3}$

1. Department of Prosthodontics, Faculty of Dentistry, Tabriz University of Medical Sciences, Iran

2. Prosthodontist, Private Office, Tabriz, Iran

3. Dentist, Private Office, Tabriz, Iran

\begin{abstract}
Introduction: Marginal adaptation of a crown is an important factor affecting its clinical acceptability and durability; also, poorly fitting cast restoration enables bacterial plaque accumulation and leads to teeth caries and periodontal deterioration.

Purpose: The purpose of this study was to evaluate marginal adaptation of 4all, Verabband2, $\mathrm{T} 3$ and Supremcast $\mathrm{V}$ base metal alloys before and after porcelain firing.

Material and Method: In this experimental study, a sound maxillary first premolar was prepared with chamfer and shoulder-bevel finish lines in palatal and buccal surfaces, respectively. Then the metal die was fabricated. Six points were marked $1 \mathrm{~mm}$ apical to the margin in the buccal and palatal surfaces. Forty impressions were taken from metal die by polyether impression material. Then, 10 frameworks were fabricated with each alloy type on stone dies. The vertical margin discrepancy between the frameworks and the marked points on metal dies were measured before and after porcelain firing. Paired sample t-test and One-way ANOVA, followed by multiple comparison tests (Tukey test) were used to evaluate data. In this study, statistical significance was defined at $p<0.05$.

Results: Before porcelain firing, T3 alloy showed the lowest marginal discrepancy on chamfer finish line $(13.13 \pm(1.26))$; but, the highest values were for Supermcast $V$ copings and shoulder-bevel finish after porcelain application (30.83 \pm (2.01)). The mean marginal discrepancies of buccal and palatal surfaces before porcelain application were significantly lower for all alloy types $(p<0.001)$.

Conclusion: The marginal adaptation of all four metal alloys was clinically acceptable and the thermal cycles of porcelain firing affected marginal adaptation.
\end{abstract}

Keywords: Crown; Marginal adaptation; Metal ceramic alloys

\section{Corresponding author:}

Roodabeh Koodaryan

Department of Prosthodontics, Faculty of Dentistry, Tabriz University of Medical Sciences, Iran

Email: koodaryan@gmail.com Tel: +989144161642

Receive date: 2014-11-01| Accept date: 2014-11-20| Publish date: 2014-11-26

DOI: 10.7575/aiac.abcmed.15.03.02.06 


\section{Introduction}

The marginal fit is vital to success and longevity of any metal ceramic restoration. Whereas, marginal inaccuracies, in terms of poorly fitting cast restoration, enable bacterial plaque accumulation and lead to teeth caries and periodontal deterioration (1-3).

The marginal accuracy of metal ceramic restorations has been the focus of various investigations. There are several studies on the marginal fitness of cast crowns from noble alloys (4-6). Although there is consensus between various investigators about clinically acceptable marginal accuracy, Mc Lean and Von Fraunhofer reported that a marginal discrepancy of 120 micrometer should be the limit of clinical acceptability (7).

Many factors contribute to marginal changes of a cast restoration. Any one of the stages of porcelain application may lead to casting distortion and adversely influence marginal fit (8). Material thickness and type of metal also affect marginal accuracy (9-11).

To date, a majority of metal ceramic restorations constructed clinically are based on Nickel Formulations. In addition to higher stiffness, most of the compositional elements are readily available in the country, and unit metal cost of these materials is substantially lower than gold based alloys, so base metal alloys have significant economic advantages over noble alloys and are widely used. Besides, physical properties of base metal alloys such as stiffness are decidedly superior to gold based alloys. Supposedly, the reduced modulus of elasticity of these alloys makes it possible to reduce the cross sectional thickness of casting, thereby leaving more space for the porcelain (12). However, no report has compared the marginal gap of various contemporary base metal alloys and the effect of firing porcelain on the resultant marginal accuracy of these base metal alloys. Therefore, the purposes of this study was to compare the marginal gap of metal ceramic crowns cast from four different base metal alloys and evaluate them after porcelain application.

\section{Materials and methods}

One sound extracted maxillary first premolar was cleaned and embedded in autopolymerizing resin block (Acropars 200, Tehran, Iran). The resin was extended within 3 $\mathrm{mm}$ of labial cemento-enamel junction. The tooth was prepared with a circular $1.5 \mathrm{~mm}$ wide palatal chamfer, buccal shoulder finish line with a bevel and an occlusal reduction of $2 \mathrm{~mm}$. All sharp angles were smoothed and the edge of margin was placed $0.5 \mathrm{~mm}$ apical to the cement-enamel junction. A custom impression tray with a $2 \mathrm{~mm}$ relief was made from autopolymerizing acrylic resin and impression of the prepared tooth was made with polyether (Impregum, 3M ESPE, USA) impression material (Fig 1). The impression was poured with an autopolymerizing resin (Duralay, GC America Inc, USA) as a pattern for fabrication of a metal die. Then, the master die was cast with a base metal alloy (Sankin Nonberyllium, Denstply, Japan).

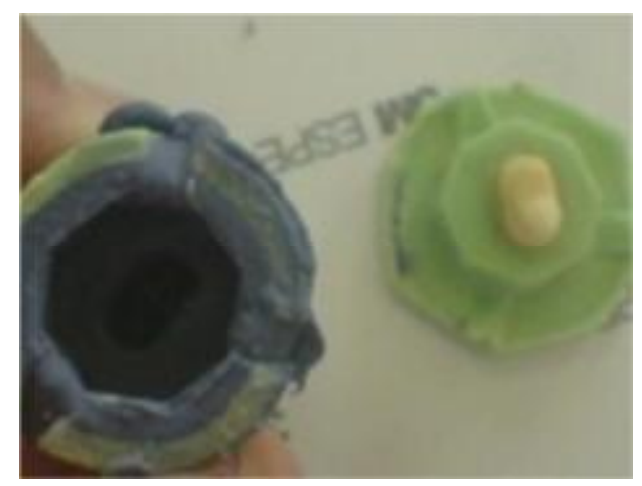

Figure 1: Impression taking from prepared tooth with custom tray and polyether impression material

Six identifiable reference points were made on the die at approximately $1 \mathrm{~mm}$ apical to the 
finish line of the metal die, denoting the midlabial, mesiolabial, distolabial, midlingual and mesiolingual, distolingual surface of the die (Fig 2). Forty custom impression trays were made for the die and impressions of the die were made with polyether impression material. Working dies were poured with type IV extra hard stone (DEGO, Bellavest T, Germany).

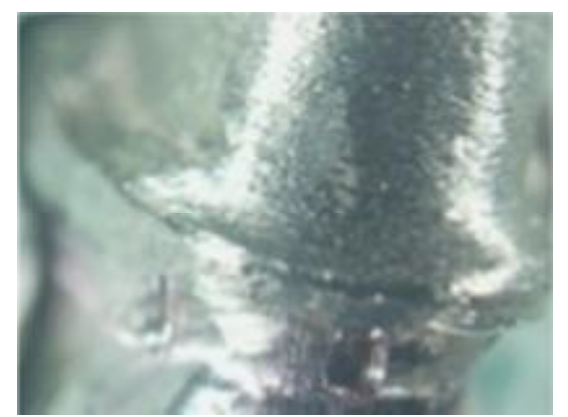

Figure 2: Reference points were made on the metal die $1 \mathrm{~mm}$ apical to the finish line

Two coats of die spacer were applied for the metal ceramic crowns. To ensure a uniform thickness of the wax patterns, wax dipping technique was used. Immersion of die in a wax bath would provide $0.5 \mathrm{~mm}$ thick standard wax patterns. Wax patterns were contoured according to shillingburg metal ceramic waxing technique. $^{13}$

Marginal discrepancy of all specimens was measured on the original metal die at six marked locations near the margin of the metal die. Seated on a positioning device, all predetermined marks were detected by means of a stereomicroscope (Stereo microscope Olympus SZX9, Olympus, Japan) at $\times 228$ magnification and a digital camera of the microscope captured the image. With the image processing software (Olysia zoom, Olympus, Japan) the vertical distance between the outer most point of margin of the copings and the external line angle of the chamfer was recorded in micrometer (Fig 3 ).
Then, wax specimens were assigned in 4 group, each representing one metal alloys in this study (Table 1). After casting and divesting the copings, they were evaluated at $\times 4$ magnifications for any imperfection or nodules. Final finishing and polishing were performed regarding Shillingburg finishing protocol. ${ }^{13}$ Then, their thickness were controlled for equivalency with metal gauge (Pak Surge, Sialkot, Pakistan).

\begin{tabular}{cccc}
\hline Group & $\begin{array}{c}\text { Metal } \\
\text { Alloys }\end{array}$ & Manufacture & $\begin{array}{c}\text { Proper } \\
\text { ties }\end{array}$ \\
\hline A & 4All & $\begin{array}{c}\text { Ivoclar } \\
\text { Vivadent AG, } \\
\text { Schaal, } \\
\text { Liechtenstein }\end{array}$ & $\begin{array}{c}\text { Non } \\
\text { Beryllium }\end{array}$ \\
\hline B & $\begin{array}{c}\text { Verab } \\
\text { ond 2 }\end{array}$ & $\begin{array}{c}\text { Albadene Co, } \\
\text { NY, USA }\end{array}$ & $\begin{array}{c}\text { Non } \\
\text { Beryllium }\end{array}$ \\
\hline C & $\begin{array}{c}\text { Super } \\
\text { mcast V }\end{array}$ & $\begin{array}{c}\text { American } \\
\text { Dent-All Inc, NY, } \\
\text { USA }\end{array}$ & $\begin{array}{c}1.9 \% \\
\text { Beryllium }\end{array}$ \\
\hline D & T3 & $\begin{array}{c}\text { Ticonium- } \\
\text { CMP, New York, } \\
\text { USA }\end{array}$ & $\begin{array}{c}1.8 \% \\
\text { Beryllium }\end{array}$
\end{tabular}

Table 1: Metal alloys used in this study

Alloy treatments for porcelain applying, opaque, dentin and glaze firing were performed according to the manufacturer's instruction (Ceramco II, Ceramco Inc., Burlington, NJ, USA). Then measurements of marginal discrepancies were repeated after porcelain firing cycles at the same sites.

To have comparable porcelain restorations, a silicone guide was made over the first fabricated porcelain full contour restoration using putty materials (Speedex, Asia Chemi Teb, Tehran, Iran). Then, it was used to evaluate and adopt the following porcelain restorations.

The mean of the marginal discrepancies was recorded in each group and the values of the 
ten specimens in each group were averaged for marginal discrepancy values of that group. Paired sample t-test was used to evaluate marginal adaptation of each alloy before and after porcelain firing. Comparison of differences in marginal discrepancies of various finish lines was carried out by ANOVA. When a statistically significant difference was detected, Tukey test (post hoc test) was applied to determine the significance of statistical difference between the means of various distances. Statistical significance was set at $\mathrm{P}<0.05$.

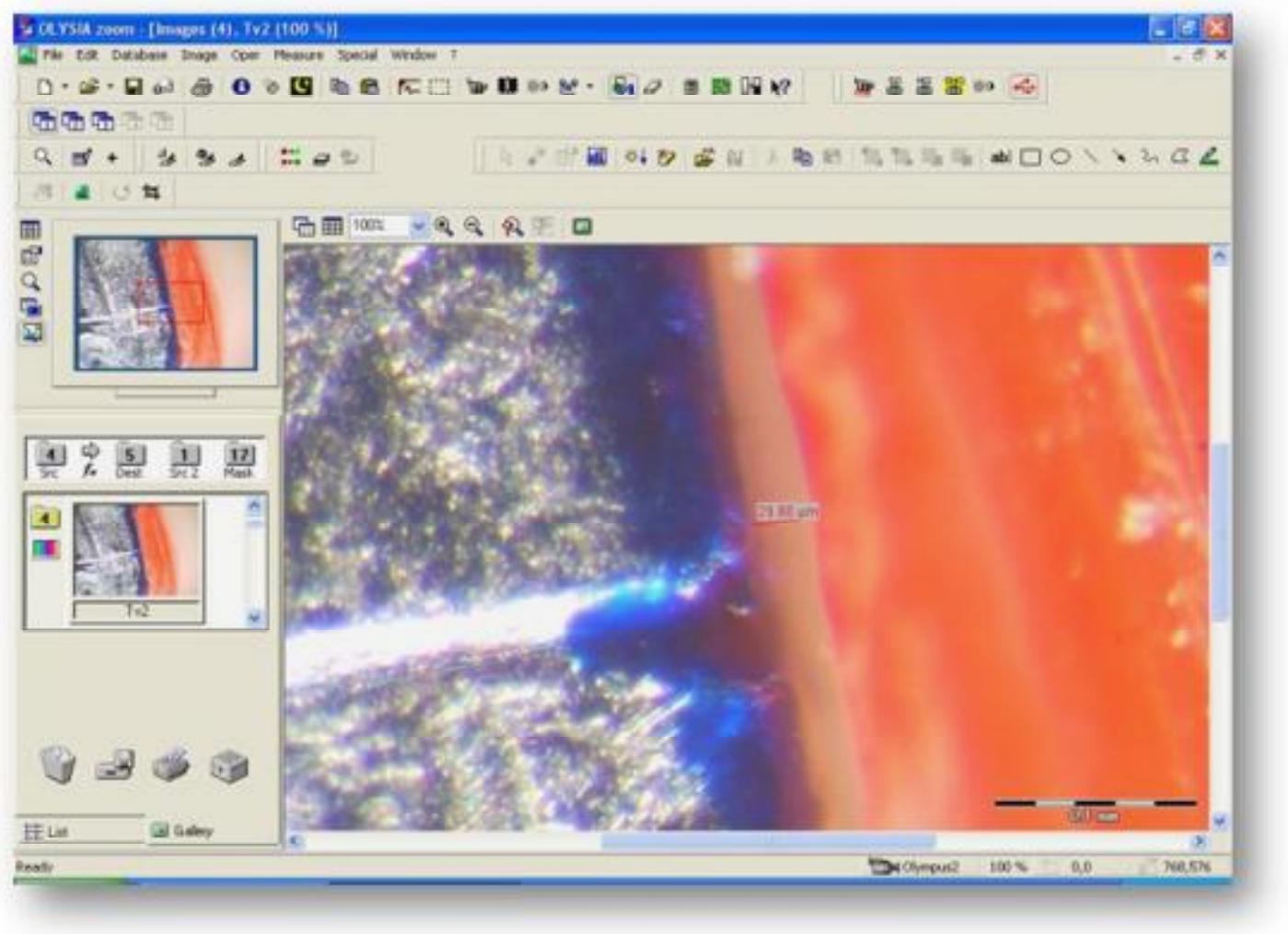

Figure 3: Gap measurement under stereomicroscope

\section{Results}

The mean values and standard deviations (SD) of marginal discrepancy before porcelain firing and after opaque and dentin layering cycles were calculated (Table 2). In all four evaluated alloys marginal discrepancy increased after porcelain application $(P<0.001)$. ANOVA showed that both metal selection and firing stage significantly influenced the measured marginal discrepancy. All four alloys yielded comparable marginal discrepancy. Before porcelain application, T3 alloy had the lowest marginal discrepancies with both finish line designs, but 4All and Verabond 2 had the greatest discrepancy values with chamfer and shoulder finish line, respectively. After porcelain firing, T3 and Supermcast $V$ had the lowest and greatest gaps, respectively.

\section{Discussion}

A wide range of values for measurements of marginal discrepancies is reported in the literature, ranging from $4 \mu \mathrm{m}$ to over $100 \mu \mathrm{m}$. However marginal gap value less than $50 \mu \mathrm{m}$ is considered clinically acceptable for cast restorations $(7,14,15)$. According to this 
criterion, all four metal alloys evaluated in marginal adaptation.

current study demonstrated clinically acceptable

\section{AII}

Verabond 2

T3

Supermcast $\mathbf{V}$

\begin{tabular}{lcllll}
\hline Before Porcelain Firing & $\begin{array}{c}\text { Shoulder } \\
\text { with } \\
\text { bevel }\end{array}$ & $18.00 \pm(2.77)$ & $19.34 \pm(4.52)$ & $\begin{array}{l}13.15 \pm \\
(1.45)\end{array}$ & $14.16 \pm(1.53)$ \\
\cline { 2 - 6 } & Chamfer & $20.60 \pm(4.52)$ & $17.96 \pm(2.69)$ & $\begin{array}{l}13.13 \pm \\
(1.26)\end{array}$ & $13.23 \pm(1.29)$ \\
\hline After Porcelain Firing & $\begin{array}{c}\text { Shoulder } \\
\text { with } \\
\text { bevel }\end{array}$ & $29.66 \pm(3.62)$ & $30.66 \pm(5.88)$ & $\begin{array}{l}25.80 \pm \\
(2.50)\end{array}$ & $30.83 \pm(2.01)$ \\
\cline { 2 - 6 } & Chamfer & $27.53 \pm(3.73)$ & $26.63 \pm(2.98)$ & $\begin{array}{l}23.13 \pm \\
(1.64)\end{array}$ & $29.02 \pm(2.79)$ \\
\hline
\end{tabular}

Table 2: Mean and standard deviation of marginal gap before and after porcelain firing four each study group

In this study, the first and second objectives were to compare marginal opening values of different alloy types and investigate effect of porcelain firing on marginal gap changes, respectively. According to the results, the lowest marginal discrepancy value was measured before porcelain application and was recorded for T3 alloy and increased in order of supermcast V, Verabond 2 and 4All. Besides, porcelain firing on metal copings increased the measured discrepancy.

Similar methodology was used by Teteruck and Mumford on Au-Pt-Pd alloy copings, resulting in 12 to $15 \mu \mathrm{m}$ average marginal gap (16). Similar to our study Boeing conducted a study on the marginal adaptation of titanium castings. They demonstrated that the mean marginal discrepancy of copings not subjected to the porcelain firing cycles was $3 \mu \mathrm{m}$ and increased to 67 after porcelain application (17). Also Buchanan and Svare reported a mean marginal discrepancy of $68 \mu \mathrm{m}$ for non-precious alloys which was larger than precious alloys ( 8 $\mu \mathrm{m})$ (18).

There is a substantial lack of consensus regarding marginal misfit in literature. The disagreement is to some extent related to the variations in the study set up. On the other hand, the metal alloy types, dental laboratory procedures, manual skills and experience of dental technician greatly influence the outcome. Unfortunately, studies that have examined the gap of different non gold alloys are in short. Therefore, direct comparison between similar published studies is limited. Consequently, complete argument is speculative and could not answer the deficiencies. 
Based on our study porcelain addition on the metal copings increased marginal opening and the difference was significant. Most of the previous reported studies have shown an increase in marginal discrepancy during porcelain application, but the precise reason of this distortion is inexplicable. Majority of changes occurs during oxidation cycles which allow the release of stored stresses. This finding is in accordance with Campbell et al. who associated the distortion to the effect of added stress on alloys released during castings, grinding or polishing phases (8). Another influencing factor may be the difference in thermal contraction between the metal coping and the porcelain, leading in distortion as the restoration cools (9-11).

The third objective of this study was to evaluate the effect of finish line design on the marginal discrepancy of the porcelain fused to metal restorations during the firing cycles. The greatest marginal discrepancy was related to labial shoulder finish line design accompanied with a bevel compared to chamfer finish line. Similar to this study, Pera et al (19) showed that a chamfer preparation produced significantly smaller marginal gaps than could be achieved compared to a shoulder finish line. As metal framework is thinner in shoulder finish line with bevel than lingual chamfer reinforced with $3 \mathrm{~mm}$ thick buttressing shoulder, more distortion is expected. The conclusions of the other studies were contradictory. They found smaller marginal gaps when a shoulder preparation was used.
Mc Lean and Wilson disapproved the application of finish line bevels for metal ceramic restoration since a bevel of $10-20$ degrees is needed to significantly improve restoration fitness. In addition, the finish line must be deep subgingivally to hide the metal collar which is not compatible with biologic requirement (10). According to Rosner, shoulder finish lines with bevel reduce inaccuracies of casting and cementation (20) Similarly, Johnston (21) found that a bevel allows better mechanical adaptation of the casting. Fauncher, similar to Shillingburg, concluded that shoulder finish lines with or without a bevel produced significantly less marginal distortion than did chamfer $(22,23)$.

Despite the limitations of this study, all alloys in this investigation exhibited acceptable clinical marginal gap while the best marginal fitness belonged to T3 alloy.

\section{Conclusion}

Porcelain firing cycles affect marginal adaptation; however, alloy and finish line types do not affect it significantly. Marginal adaptation of the four evaluated alloys was clinically acceptable.

\section{References}

1. Donovan TE. Factors essential for successful all-ceramic restorations. J Am Dent Assoc 2008; 139:14S-8S.

2. Felton DA, Kanoy BE, Bayne SC, Wirthman GP.: Effect of in vivo crown margin discrepancies on periodontal health. J Prosthet Dent 1991; 65:357-64.

3. Tuntiprawon M, Wilson PR: The effect of cement thickness on the fracture strength of all ceramic crowns. Aust Dent J 199; 40:17-21. 
4. Boyle JJ, Naylor WP, Blackman RB. Marginal accuracy of metal ceramic restorations with porcelain facial margins. J Prosthet Dent 1993; 69:19-27.

5. Weaver JD, Johnson GH, Bales DJ. Marginal adaptation of castable ceramic crowns. J Prosthet Dent 1991; 66:74753.

6. Hung SH, Hung KS, Chappell RP. Marginal fit of porcelain-fused-to-metal and two types of ceramic crown. J Prosthet Dent 1990; 63:26-31.

7. McLean JW, Von Fraunhofer JA. The estimation of cement film thickness by an in vivo technique. Br Dent J 1971; 131:107-11.

8. Campbell SD, Pelletier LB. Effect of firing cycle and surface finishing on distortion of metal ceramic casting. J Prosthet Dent 1995; 74:476-81.

9. Iwashita AH, Kuriki HT, Husuo T. Studies on dimensional accuracy of porcelain fused to precious metal crowns, the influence of the porcelain to the metal coping on the porcelain fusing procedure. Shigaku 1977; 65:110-25.

10. Mclean JW. Wilson AD. But joint versus beveled gold margin in metal ceramic crowns. J Biomed Mater Res 1980; 14:239-50.

11. Konsrantoulakis E, Nokojima H. Marginal fit and surface roughness of crown made with an accelerated cast technique. J Prosthet Dent 1998, 80:337-45.

12. Leinfelder KF. An evaluation of casting alloys used for restorative procedures. J Am Dent Assoc 1997; 128:37-45.

13. Shillingburg HT, Sather DA, Wilson EL, Cain JR, Mitchell DL, Blanco LJ, Kessler JC. Fundamentals of fixed prosthodontics. 4th edition. Quintessence Publishing. 2012, 449-57.

14. Christensen GJ. Marginal fit of gold inlay castings. J Prosthet Dent 1966; 16:297-305.

15. Lofstrom LH, Barakat MM. Scanning electron microscopic evaluation of clinically cemented cast gold restorations. J Proshet Dent 1989; 61:664-9.

16. Teteruck WR, Mumford G. The fit of certain dental casting alloys using different investing materials and techniques. J Proshet Dent 1966; 16:910-27.

17. Boening K, Wolf BH, Schmidt AE, Kastner K, Walter MH. Clinical fit of procera Allceram crowns. J Prosthet Dent 2000; 84:419-24.

18. Buchanan WT, Svare CW, Turner KA. The effect of repeated firings and strength on marginal distortion in two ceramometal systems. J prosthet Dent 1981; 45:502-6.

19. Pera P, Gilodi S,Bassi F,Carossa S. In vitro marginal adaptation of alumina porcelain ceramic crowns. J prosthet Dent 1994; 72:585-90.

20. Rosner D (1963). Function, placement and reproduction of bevel for gold castings. J Prosthet Dent 1963; 13:11606.

21. Johnston JF, Mumford G, Dykema RW. The porcelain veneered gold crown. Dent Clin North Am 1963; 7:853-64.

22. Shillingburg HT, Hobo S, Fisher DW. Preparation design and margin distortion in porcelain fused to metal restorations. J Prosthet. Dent 1973; 29:276-84.

23. Faucher RR, Nicholls JI. Distortion related to margin design in porcelain fused to metal restorations. J prosthet dent 1980; 43:149-55. 